\title{
A history of extreme disturbance affects the relationship between the abundances of nitrifiers in soil
}

\author{
Stephanie D. Jurburg ${ }^{1,2}$ (D) - Féline L. Assemien ${ }^{3,4}$ • Léa Beaumelle ${ }^{2}$. Joana F. Salles ${ }^{1}$ • Jan Dirk Van Elsas ${ }^{1}$. \\ Xavier Le Roux ${ }^{3}$
}

Received: 30 April 2020 / Revised: 1 July 2020 / Accepted: 9 July 2020 / Published online: 28 July 2020

(C) The Author(s) 2020

\begin{abstract}
To understand how and to what extent single or multiple perturbations can alter the relationships between the abundances of different nitrifier groups and nitrification, soil microcosms were exposed to six disturbance treatments: a heat shock, cold shock, or control conditions applied to undisturbed soils or to soils that had previously been subjected to a first heat shock. We monitored the recovery of the abundances of four main nitrifier groups (ammonia-oxidizing archaea and bacteria, AOA and AOB, respectively, and Nitrobacter and Nitrospira nitrite oxidizers) as well as nitrification activity for 25 days. AOA were sensitive to cold shocks, whereas AOB were not; the latter were sensitive to heat shock. Despite the variations, both groups were resilient to the first disturbance. In contrast, Nitrobacter was affected by both disturbances, whereas Nitrospira was resistant to both shocks. Prior exposure to a heat shock affected each group's responses as well as the relationships between them. For example, AOB were more vulnerable to heat shock in pre-exposed soils, whereas under the same circumstances, AOA were resilient. Nitrification activity was resistant to the first disturbances, but a legacy effect was observed, and nitrification was highest in Heat-Heat and lowest in Heat-Cold treatments. Overall, our study shows that within soil nitrifiers, temporal patterns and legacy effects interact to result in complex disturbance responses.
\end{abstract}

Keywords Soil $\cdot$ Nitrification $\cdot$ Nitrogen cycle $\cdot$ Ammonia oxidation $\cdot$ Nitrite oxidation

\section{Introduction}

Nitrification, the oxidation of ammonia to nitrite and nitrate, is an essential ecosystem function, tied to fertility and plant

Electronic supplementary material The online version of this article (https://doi.org/10.1007/s00374-020-01491-8) contains supplementary material, which is available to authorized users.

Stephanie D. Jurburg

s.d.jurburg@gmail.com

1 Microbial Community Ecology Cluster, Groningen Institute for Evolutionary Life Sciences (GELIFES), University of Groningen, Nijenborgh 7, 9747 AG Groningen, Netherlands

2 iDiv (German Centre for Integrative Biodiversity Research Halle-Jena-Leipzig), Deutscher pl. 5E, 04103 Leipzig, Germany

3 Université de Lyon, INRAe, CNRS, Université Lyon 1, Laboratory of Microbial Ecology (UMR 5557 CNRS, UMR 1418 INRAe), 43 bd du 11 Novembre 1918, Cedex, 69622 Villeurbanne, France

4 Université Nangui Abrogoua, Unité de formation et de Recherche des Sciences et Technologies des Aliments, Laboratoire de Biocatalyse et des Bioprocédés, 02, BP 801, Abidjan 02, Côte d'Ivoire productivity in terrestrial ecosystems in general. In soil, nitrification rates partly determine whether $\mathrm{N}$, added through urea or ammonium fertilizers, will benefit plants or will be leached (as nitrate) or emitted into the air (i.e., as nitrous oxide; Wang et al. 2015). Nitrification is a two-step process, each of which is generally carried out by distinct groups of microbes (although a recently discovered group of bacteria from the genus Nitrospira is able to perform both steps, likely at low rates) (Daims et al. 2015; van Kessel et al. 2015; Dimitri Kits et al. 2017; Xia et al. 2018). The conversion of ammonia to nitrite is catalyzed by ammonia-oxidizing bacteria (AOB) and/or archaea (AOA) (Leininger et al. 2006). Nitrite oxidation, the conversion of nitrite to nitrate, is the second step of nitrification which is catalyzed by several phylogenetically conserved groups of nitrite-oxidizing bacteria (NOB). Ammonia oxidizers (AO) and NOB depend on each other for substrate supply and removal of toxic nitrite from the environment, respectively (Stempfhuber et al. 2016).

Ammonia oxidation is performed by the bacterial genera Nitrosomonas, Nitrosospira ( $\beta$-Proteobacteria), and Nitrosococcus ( $\gamma$-Proteobacteria; Purkhold et al. 2000) and by archaea from the phylum Thaumarchaeota (Leininger et al. 2006). Both AOB and AOA harbor the ammonia 
monooxygenase gene $(a m o A)$, which serves as a functional gene marker for the identification of ammonia oxidizers in environmental samples (Leininger et al. 2006). Studies targeting the amoA gene have revealed ecological preferences of these functional groups. AOA, which are facultative ammonia oxidizers (Martens-Habbena et al. 2009), thrive at low ammonium concentrations (Simonin et al. 2015) and low oxygen concentrations (Hatzenpichler 2012). Furthermore, AOA are the dominant ammonia oxidizers in acidic soils (Prosser and Nicol 2012) and in the lower soil layers. In contrast, AOB are favored under high soil $\mathrm{N}$ availability (Di et al. 2009; Sterngren et al. 2015; Ma et al. 2016).

Nitrite oxidation is generally not the limiting step in nitrification (Schramm et al. 1998; Okabe et al. 1999), and nitrite oxidizers have been less extensively studied than ammonia oxidizers. Several lineages of NOB have been identified, belonging to the $\alpha-, \beta,-, \gamma-$, and $\delta$-Proteobacteria (including Nitrobacter), as well as to the phyla Nitrospirae, Chloroflexi, and Nitrospinae (Kitzinger et al. 2018). In soil, Nitrospira and Nitrobacter are the most common NOB (Attard et al. 2010). Bacteria from both groups have been isolated from soil and identified from 16S rRNA gene sequences (Attard et al. 2010; Stempfhuber et al. 2016). Nitrospira are able to persist at lower nitrite concentrations than Nitrobacter which grow more rapidly under high N supply (Kim and Kim 2006; Le Roux et al. 2016).

As the patterns of abundance in ammonia and nitrite oxidizers are revealed, the relationships between these two functional groups have come into focus (Leininger et al. 2006; Palatinszky et al. 2015). More generally, the abundance of Nitrospira has been found to correlate to that of AOA (Pester et al. 2014; Ma et al. 2016; Stempfhuber et al. 2016), while the abundance of Nitrobacter has often been associated with that of AOB (Placella and Firestone 2013; Ma et al. 2016). Nevertheless, in other cases, AOB abundances were also correlated to Nitrospira abundance (Prosser and Nicol 2012; Xia et al. 2011). Some of these nitrifier groups may have different environmental preferences. For example, one study found that as the temperature of lake microcosms was increased from 15 to $35^{\circ} \mathrm{C}$, the abundance of AOA increased linearly, while AOB abundance decreased (Zeng et al. 2014). More generally, changes in the relative abundances of different nitrifier groups have been observed in response to temperature changes (Avrahami and Conrad 2003; Tourna et al. 2008), fertilization (Avrahami et al. 2003; Xie et al. 2014; Jia et al. 2019), season (Stempfhuber et al. 2016), grazing (Pan et al. 2018), and tillage (Attard et al. 2010). Contrasted responses of different nitrifier groups to disturbances can result in changes in their relative contributions to nitrification. For instance, NOB are more sensitive than ammonia oxidizers to disturbances like steam disinfestation (Roux-Michollet et al. 2008) or other severe disturbances (Gelfand and Yakir 2008; Nowka et al. 2014), which can lead to nitrite accumulation in soil (Roux-Michollet et al. 2008). The relationship between the microorganisms involved in the first and second steps of nitrification may thus be broken in response to disturbances.

While the post-disturbance resistance and resilience of the abundances of soil nitrifier groups have previously been studied, the effect of contrasted disturbance histories with succession of a same disturbance or of different disturbances on the relationships between different nitrifier groups has rarely been explored (but see Calderón et al. 2018). Previously, we showed that the microbiomes of soils (i.e., bacteria and archaea) subjected to two identical disturbances recovered more rapidly from the second disturbance than from the first and that when the two disturbances were different, their effect on the community was multiplicative (Jurburg et al. 2017a). In order to examine the effect of repeated perturbations on the recovery of "narrow" soil functions, we exposed soil microcosms to six disturbance regimes: a heat shock, cold shock, or control conditions applied to undisturbed soils or to soils previously subjected to a first heat shock. To exclude the possibility of previous exposure and adaptation to the applied disturbances, we used extreme heat $\left(65^{\circ} \mathrm{C}\right)$ and extreme cold ($80^{\circ} \mathrm{C}$ ) shocks. We monitored the abundance of AOB, AOA, Nitrospira and Nitrobacter, and nitrification activity for 25 days after disturbance. Our aims were to (a) describe the ecological response of each nitrifier group to single heat and cold shocks and (b) test the effect of compounded perturbation on the nitrifying community's ability to perform nitrification. In particular, we hypothesized that in soils with a heat shock legacy, the nitrifiers selected by this first heat disturbance would be better adapted to this disturbance so that a second heat shock would have a less drastic effect on the nitrifiers. Conversely, if a tradeoff exists between microbial traits that are important to thrive under heat versus cold disturbances, a cold shock would have a more drastic effect following a first heat shock than in the absence of a heat disturbance legacy. Finally, if disturbance resulted in the drastic reduction of the dominant group of ammonia of nitrite oxidizers, we expected to see a brief decrease in nitrification activity, followed by the gradual recovery of this function. This study is the first to evaluate how temporal responses and legacy effects interact to modulate the response of nitrification-associated communities to disturbance.

\section{Methods}

\section{Microcosm experiment and sampling}

Samples from a previous microcosm experiment were used (Jurburg et al. 2017a). Briefly, soil samples were obtained from a well-characterized agricultural field in Buinen, the Netherlands ( $52^{\circ} 55$ 'N, 6 $\left.6^{\circ} 49^{\prime} \mathrm{E}\right)$, in April 2013. The field 
consisted of a loamy sand soil (sand:silt:clay of 50:20:30) with a $\mathrm{pH}\left(\mathrm{H}_{2} \mathrm{O}\right)$ of 5.04. The seasonal variations in organic matter, nitrate, and ammonium have been previously described for this soil (Pereira e Silva et al. 2012). Samples were taken from the top $15 \mathrm{~cm}$ of soil with shovels and homogenized by sieving through a $4 \mathrm{~mm}$ sieve. A total of 87 microcosms were prepared by adding $50 \mathrm{~g}$ fresh soil to $200 \mathrm{ml}$ glass jars, which were then covered with a loose aluminum foil cap. Soils were maintained at $21^{\circ} \mathrm{C}$, partially shielded from light, and moisture was maintained at $65 \%$ with sterile water and adjusted weekly throughout the experiment. Soils were allowed to stabilize in the microcosms for 2 weeks prior to the experiment. Sampling was done destructively in triplicate, and all microcosms were incubated for the same duration until sampling.

To evaluate the effect of disturbance history on microbial nitrification, we prepared all microcosms simultaneously and divided them into two groups: 45 microcosms were initially maintained at control conditions, while 42 microcosms were exposed to a first heat shock. Jars were uncovered, placed in an 800-watt microwave oven (R201ww Sharp, Utrecht, the Netherlands), and subjected to $90 \mathrm{~s}$ of heating at maximum intensity (yielding an average temperature of $\sim 65{ }^{\circ} \mathrm{C}$ ). Following this first round of disturbances, soils were allowed to recover for 24 days. On the 25th day, control and initially disturbed microcosms were subjected to either an additional, identical heat shock, a cold shock (which consisted of placing jars in a $-80^{\circ} \mathrm{C}$ freezer for $6 \mathrm{~h}$ ), or control conditions. This led to a total of 6 treatments (Control-Control, Control-Heat, Control-Cold, Heat-Control, Heat-Heat, and Heat-Cold). Microcosms were allowed to recover for additional 25 days after the second round of disturbances and were sampled destructively on days $1,11,18$, and 25 . The 25 -day recovery period was selected because we previously found that following single, identical heat shocks, community turnover slowed down after 25 days, whereas the community composition had not approached its pre-disturbance conformation (Jurburg et al. 2017b). This period was thus considered optimal to assess possible legacy effects.

\section{Soil DNA extraction and functional gene quantification}

DNA was extracted from $0.5 \mathrm{~g}$ of fresh soil using the MoBio PowerSoil DNA Extraction Kit (MoBio Laboratories, Carlsbad, CA, USA) following the manufacturer's instructions, with three additional rounds of bead-beating for $30 \mathrm{~s}$ (Mini-Bead Beater, BioSpec Products, Bartlesville, OK, USA). The quality and concentration of the resulting DNA were assessed by electrophoresis on a $0.8 \%$ agarose gel with a SmartLadder (Eurogentec, Liege, Belgium).

Quantitative PCR (qPCR) was used to estimate the total numbers of archaea, bacteria, $\mathrm{AOA}, \mathrm{AOB}$, and $\mathrm{NOB}$
(Nitrobacter and Nitrospira). Archaeal and bacterial abundances were estimated by quantifying 16S rRNA gene copies with primers 771F/957R (Ochsenreiter et al. 2003) and 16SFP/16SRP (Bach et al. 2002, Supplementary S1). Ammonia oxidizer abundances were estimated as the abundances of bacterial and archaeal amoA genes, using primers amo23F (Tourna et al. 2008) and crenamo616r (Nicol et al. 2008) for AOA and amoA-1F (Stephen et al. 1999) and amoA-2R (Rotthauwe et al. 1997) according to Nicol et al. (2008). Nitrospira NOB were estimated by targeting a Nitrospira-specific region of the 16S rRNA gene (Graham et al. 2007). Nitrobacter abundance was estimated by targeting the $n x r A$ gene using Nitrobacter-specific primers (Wertz et al. 2008) and the qPCR protocol presented in Attard et al. (2010). Copy numbers were calculated using standard curves spanning six orders of magnitude $\left(10^{3}-10^{8}\right)$. These curves were made from reactions with linearized plasmids containing clones of each gene or gene segment analyzed and were used to calculate amplification efficiency. DNA concentrations, and standards used for each reaction are available in Supplementary Table 1. Amplification efficiency $(E)$ was calculated as $E=10^{-1 / \text { slope-1 }}$ and was greater than $90 \%$ for all runs.

\section{Nitrification activity assays}

Nitrification enzyme activity (NEA) was quantified using a modified version of Hart et al. (1994), according to Dassonville et al. (2011). Briefly, fresh soil sub-samples equivalent of $3 \mathrm{~g}$ of dried soil were suspended in $30 \mathrm{~mL}$ of $\left(\mathrm{NH}_{4}\right) 2 \mathrm{SO}_{4}\left(1.25 \mathrm{mg} \mathrm{N} \mathrm{L}^{-1}\right)$ and incubated in aerobic conditions with a rotary shaker $\left(180 \mathrm{rpm}, 28^{\circ} \mathrm{C}\right)$. Nitrate and nitrite productions were measured after $60,150,240$, and $300 \mathrm{~min}$ in triplicate. At each time point, $2 \mathrm{~mL}$ of suspension were filtered at $0.20 \mu \mathrm{m}$ and then frozen at $-18^{\circ} \mathrm{C}$ prior to analysis. Nitrate and nitrite contents of the filtrate were analyzed using ionic chromatography (DX120, Dionex, Salt Lake City, USA) with a $4 \times 250 \mathrm{~mm}$ column (IonPac AS9-HC). NEA was calculated as the linear increase in nitrate plus nitrite amount along time.

\section{Statistical analyses}

Statistical analyses were performed in R 3.2.3 (R Core Team 2014). The significance of changes in abundances in disturbed soils relative to controls was calculated with two-tailed $t$-tests. Correlations between the abundances of the different nitrifying groups for each disturbance treatment were calculated using Pearson's product moment correlation coefficients and displayed using the package corrplot (https:/github.com/ taiyun/corrplot). In order to detect changes in the relationships among the abundances of nitrifier groups and phylogenetic groups on the one hand and between the abundances of nitrifier groups and NEA on the other hand, 
according to disturbance treatment and across sampling dates, we used linear mixed effect models and compared the slopes under different disturbance treatments. A first model related the abundance of NOB to the abundance of AO, the disturbance treatment, and their interaction (considered as fixed effects), while a random effect of the sampling date was nested within treatment. We were interested in the interaction effect that would indicate if the disturbance modified the relationship between NOB and AO. Post hoc analyses were conducted to compare the slopes of the relationship for each disturbance treatment with a Tukey method for $P$ value adjustment using the R package emmeans (Lenth et al. 2018). We tested a similar model with the ratios of Nitrospira NOB to Nitrobacter NOB and of AOA to AOB. We also tested if NEA was related to the abundances of ammonia oxidizers and nitrite oxidizers and if those relationships were affected by the disturbance treatment using a similar approach. Nitrifier abundances and NEA data were log-transformed to improve normality. Model fit was checked by inspection of residual diagnostic plots. We further tested the influence of extreme values by comparing the model estimates with and without those extremes.

\section{Results}

\section{Single disturbance responses of nitrifier abundances}

To evaluate the effect of disturbances on the abundances of the four groups of nitrifiers, we first assessed their responses to single heat or cold shocks in soils without heat disturbance legacy (i.e., Control-Heat and Control-Cold). Sensitivities to heat and cold shocks differed between functional groups (Fig. 1). Significant differences between the abundances of ammonia oxidizers in disturbed and control soils were observed on day 11. At this time, AOB abundance in heatshocked soils was $14.1 \%$ of that of controls $(p=0.033)$ but was unaffected by the cold shock, remaining indistinguishable from controls throughout the experiment. In contrast, AOA abundance in heat-shocked soils was $27.7 \%$ of that found for controls $(p=0.025)$ and $6.7 \%$ of that of controls in coldshocked soils $(p<0.001)$ on day 11 . The abundances of both groups of ammonia oxidizers recovered to control levels by day 18 .

The abundance of Nitrobacter was significantly lower than in controls in heat-shocked soils on day $18(26.2 \%$ that of controls, $p=0.038$ ) and in cold-shocked soils on day 25 (32.5\% of controls, $p=0.008)$. Notably, Nitrobacter abundance did not recover from the heat shock within the period studied. The abundance of Nitrospira was not significantly affected by heat or cold shocks. No decreases in the abundances of total archaea were detected in response to any treatment $(p>0.05)$.
Similarly, the only change we observed in the abundance of bacteria was a slight decrease on day 25 in response to the heat shock $(p=0.042$, Fig. S1).

\section{The heat shock legacy effect on nitrifier abundances}

In soils which were pre-treated with a heat shock, an additional cold shock had no effect on the AOB as compared with Heat-Control soils at all time points (Fig. 1). This Heat-Cold treatment had a weak effect on AOA whose abundances were significantly lower than Heat-Control soils on day 11 (53.6\% of those in Heat-Control soils on average, $p=0.048$ ).

Soils from the Heat-Heat treatment (which were exposed to an initial heat shock and an additional heat shock) had lower abundances of AOB $(0.48 \%$ of those in Heat-Control soils on average across all time points, $p<0.001$ ), and AOB abundance did not recover during the period studied. Soils from this Heat-Heat treatment also exhibited significantly lower AOA abundances on day 11 (15\% of that found in HeatControl soils; $p=0.048$ ), and AOA abundance recovered to control levels by the end of the experiment. The abundances of Nitrobacter and Nitrospira in Heat-Heat and Heat-Cold soils did not significantly differ to Nitrobacter and Nitrospira abundances observed in Heat-Control soils. Notably, the average abundance of both Nitrobacter and Nitrospira exposed to the Heat-Heat treatment was higher than that found for Heat-Control soils.

Total archaea were significantly lower in the Heat-Cold treatment than in the Heat-Control treatment only on day 18 but exhibited no detectable response to the Heat-Heat treatment (Fig. S1). In contrast, total bacteria in the both the Heat-Heat and Heat-Cold treatments were significantly lower than in the Heat-Control on day 11. Soils from the Heat-Heat treatment were significantly higher than in the Heat-Control on days 1 and 18 ( $p<0.05$ for all comparisons, Fig. S1).

\section{Disturbance legacy effect on nitrification activity}

The high between-replicate variability observed for NEA restricted our ability to detect statistically significant treatment effects over time, and no clear effect of a single (heat or cold shock) disturbance was observed (Fig. 2). In soils previously exposed to a heat shock, NEA decreased in response to an additional cold disturbance. In these HeatCold soils, an average loss of $54 \%$ in NEA was observed relative to the controls for days 18 and 25 . By day 25 , NEA in this treatment remained significantly lower than in soils from any other treatment $(p<0.05)$. In contrast, NEA was not significantly different between Heat-Heat and HeatControl soils. 
Fig. 1 Changes in the abundances of nitrifying groups according to disturbance history. For each panel, the effects of (left) a single disturbance applied on a previously undisturbed soil and (right) the same disturbance following a first heat disturbance are presented for ammonia-oxidizing bacteria, AOB; ammoniaoxidizing archaea, AOA; and nitrite-oxidizing bacteria, NOB. Large circles indicate the mean for each treatment over time, and small circles indicate individual data points. The gene abundances are displayed as normalized by the average control values in Supplementary S4. Treatments with a legacy disturbance are displayed as dashed lines

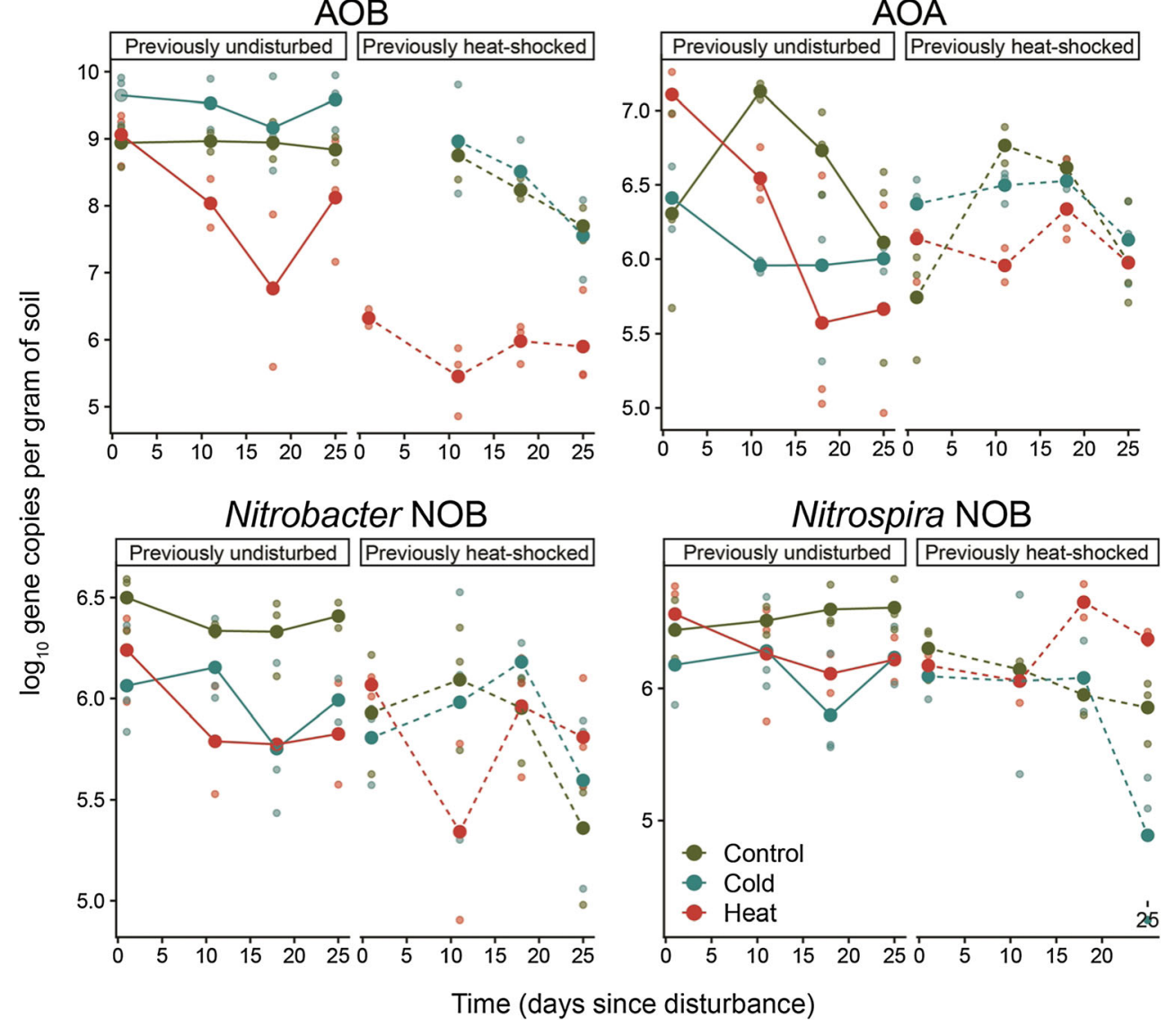

\section{Relationships between ammonia and nitrite oxidizer abundances depending on disturbance history}

In the absence of a disturbance, the abundance of AOB was significantly correlated to Nitrospira abundance $(R=0.68$, $p=0.020$ ) (Fig. 3). The relationship between AOB and Nitrospira abundances was significant across the entire experiment $(\chi 2=32.955, \mathrm{df}=1, p<0.05)$ but was modulated by treatment (interactive effect: $\chi 2=21.42, \mathrm{df}=5, p<0.05$; Fig. 3). Following a single cold shock, AOB and Nitrospira were still significantly and positively correlated, but following a single heat shock, this relationship was no longer detected, and instead significant correlations were observed between the abundances of AOA and $\mathrm{AOB}(R=0.81, p=0.004)$ and
Fig. 2 Changes in nitrification activity, NEA, according to the disturbance history. Large circles indicate the mean for each treatment over time, and small circles indicate data points. Treatments with a legacy disturbance are displayed as dashed lines

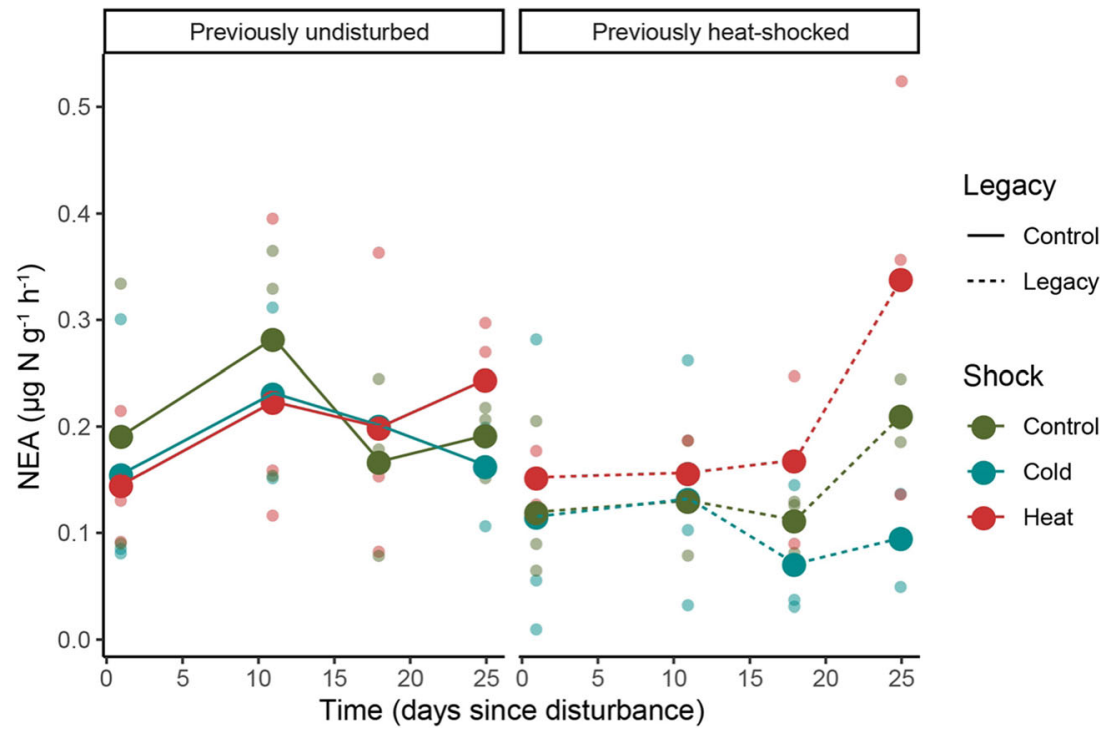


Control-Heat

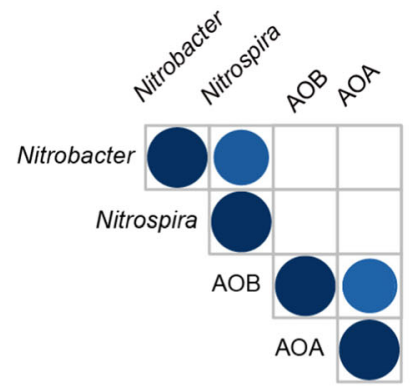

Heat-Heat

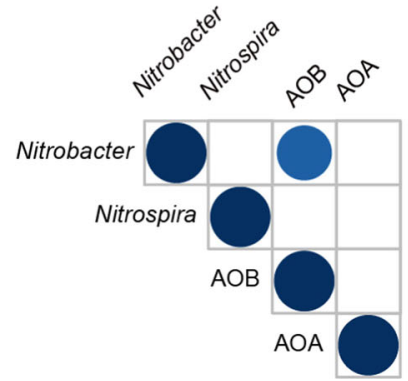

\section{Control-Cold}

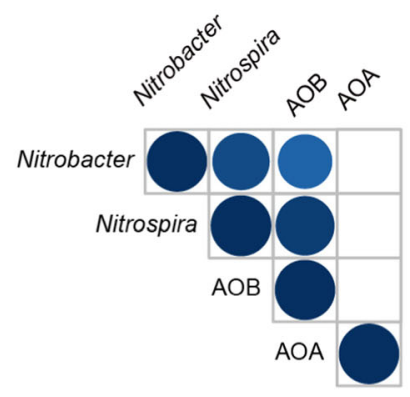

Heat-Cold

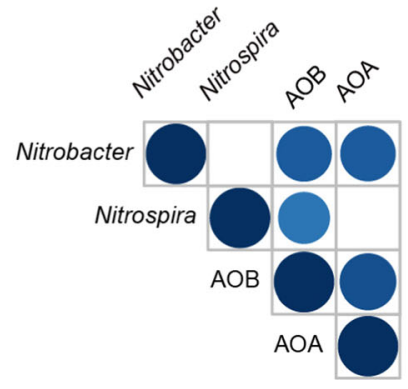

Control

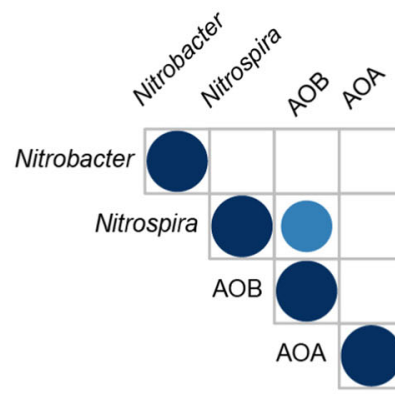

Heat-Control

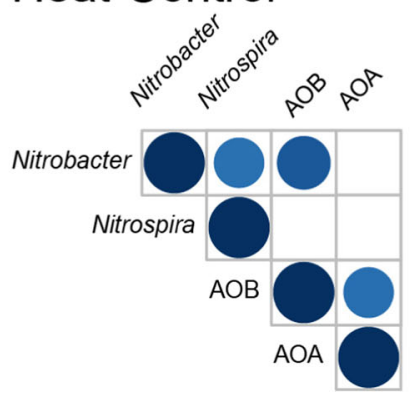

$\mathrm{R}^{2}$

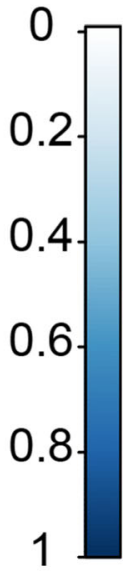

Fig. 3 Correlations between the abundances of the different nitrifying groups in recently disturbed soils. Only significant correlations $(p>0.05)$ are shown. The colored scale refers to the $R$ values of significant correlations, and the size of circles is proportional to the $R$ values ( $R>0.68$ for all displayed correlations). No significant correlations were detected for archaea and bacteria, and these were excluded from this figure
Nitrospira and Nitrobacter ( $R=0.83, p=0.002$; Fig. 3). Notably, a correlation between AOB and Nitrobacter abundances was present in the heat-shocked soils with a heat shock legacy disturbance (i.e., Heat-Heat treatment, $R=0.82, p=$ 0.047).

After a single cold shock, we detected significant correlations between both Nitrobacter and Nitrospira and AOB abundances $(R=0.80$ and $p=0.009$ and $R=0.95$ and $p<0.001$, respectively; Fig. 3 ), as well as a correlation between the abundances of NOB $(R=0.89, p=0.001)$. In Heat-Cold soils, we found that AOB abundance was significantly correlated to the abundances of Nitrobacter and Nitrospira $(R=0.84$ and $p=0.005$ and $R=0.73$ and $p=$ 0.026, respectively; Fig. 3). For this treatment, we also found a significant correlation between Nitrobacter and AOA abundances $(R=0.84, p=0.005)$ and between AOA and AOB abundances $(R=0.88, p=0.002)$. Notably, the abundance of total bacteria and total archaea did not correlate with the abundances of any functional group, for any treatment.

We also evaluated whether the sum of nitrite oxidizers changed in relation to the sum of ammonia oxidizers and whether this relationship was affected by the disturbance regimes. There was a positive relationship between the total abundances of NOB and of AO across all soil samples $\left(\chi^{2}=\right.$ $46, \mathrm{df}=1, p<0.05$; Fig. 4). More specifically, in the absence of disturbance, there was a positive relationship between total $\mathrm{AO}$ and total $\mathrm{NOB}$ (slope $=0.43, \mathrm{SE}=0.34$ ). This relationship was consistent across treatments but was modulated by disturbance history $\left(\chi^{2}=17.3, \mathrm{df}=5, p<0.05\right)$. This pattern was driven by a weakening of the relationship between NOB and AO abundances in soils exposed to a single heat shock (i.e., Control-Heat treatment, slope $=0.09, \mathrm{SE}=0.08$; Fig. 4), whereas for Heat-Heat soils, the correlation was shifted due to $\mathrm{a} \sim 100$-fold lower $\mathrm{AO}$ abundances for unaltered NOB

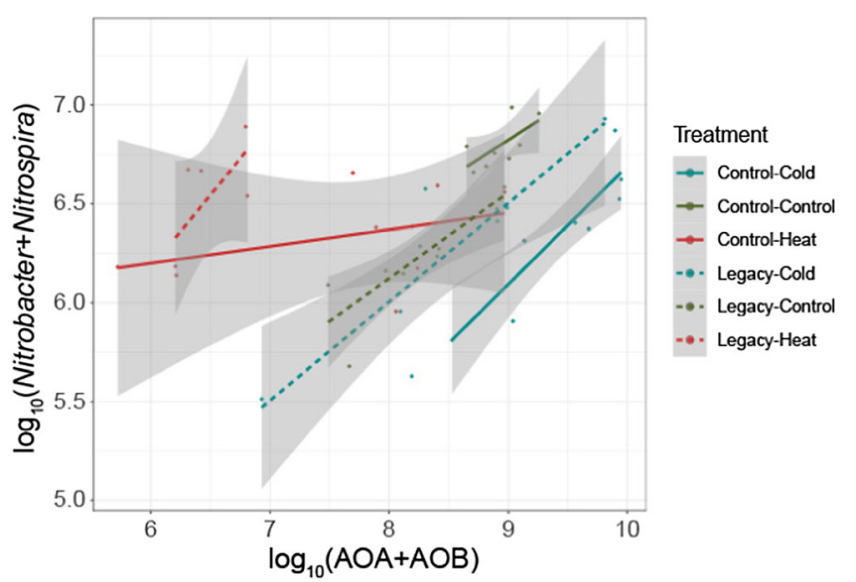

Fig. 4 Changes in the relationship between the total nitrite oxidizer abundance and total ammonia oxidizers abundance according to the disturbance history. Totals for each group were calculated as the sum (i.e., sum of ammonia-oxidizing archaea and bacteria abundances, AOA $+\mathrm{AOB})$. Lines are linear relationships for each disturbance history, and gray areas represent the $95 \%$ confidence intervals. Treatments with a legacy disturbance are displayed as dashed lines 
abundances (Fig. 4). In contrast, for Control-Cold soils, the NOB-AO relationship was shifted due to the decreased total NOB abundance without alteration of total AO abundance (Fig. 4). No such overall relationships were found for the ratios of AOA to AOB and Nitrospira NOB to Nitrobacter $\operatorname{NOB}\left(\chi^{2}=0.004, \mathrm{df}=1, p=0.95\right.$; Supplementary S2).

\section{Relationship between NEA and nitrifier abundances}

No significant correlations were detected between NEA and any of the nitrifier abundances for any treatment. We also investigated how NEA changed in relation to the sum or ratio of each group of ammonia oxidizers and nitrite oxidizers to identify whether the identity or total abundance of nitrifiers affected NEA (Fig. S3). However, there was no detectable relationship between NEA and ammonia oxidation (sum, $\chi^{2}=0.91, \mathrm{df}=1, p=0.34 ;$ ratio, $\chi^{2}=0.07, \mathrm{df}=1, p=0.79$ ) or nitrite oxidation (sum, $\chi^{2}=0.84, \mathrm{df}=1, p=0.36$; ratio, $\left.\chi^{2}=0, \mathrm{df}=1, p=0.98\right)$; NEA exhibited distinct responses to each of the regimes, on average $\left(\chi^{2}=20.36, \mathrm{df}=5, p=\right.$ $0.001)$.

\section{Discussion}

Understanding how the relationships between different microbial groups, particularly those which are important for key ecosystem functions, respond to different perturbation scenarios is crucial in the face of increasing pressures on soil ecosystems (Smith et al. 2015). To this end, we evaluated how four major groups responsible for nitrification in soil were affected by different disturbance treatments and whether a legacy of heat disturbance could modify the relationships between the abundances of these nitrifier groups. We also analyzed whether differential effects of disturbances between nitrifier groups may have cascading effects on soil nitrification activity. Using extreme heat and cold disturbances avoided any previous exposure of the soil microbial communities to similar disturbances and thus exclude the possibility of preadaptation to these disturbances, which we tested explicitly in the Heat-Heat treatment.

\section{Contrasted responses of the different nitrifier groups to single heat or cold disturbance}

AOB far outnumbered AOA, as has been previously found in other agricultural soils (Di et al. 2009; Wertz et al. 2012). However, given the low $\mathrm{pH}$ of our soil, we expected higher abundances of AOA relative to AOB (Prosser and Nicol 2012). It is likely that this is explained by the high ammonium concentration in this agricultural soil (i.e., $9.85 \mathrm{ppm}$ on average across seasons, see Pereira e Silva et al. 2012) as high ammonium concentrations generally favor AOB even in slightly acidic soils (Assémien et al. 2017). In undisturbed soils, the abundance of AOB was correlated to that of Nitrospira, a finding which aligns with previous reports (Placella and Firestone 2013; Ma et al. 2016, but see Prosser and Nicol 2012; Xia et al. 2011).

One day after disturbance, no significant effects were observed between the abundances for any of the treatments and the controls for any of the functional groups. This may be an effect of the accumulation of DNA in soil following cell lysis induced by the disturbance (i.e., relic DNA, Carini et al. 2016), which may have biased our abundance estimates immediately after disturbance. However, a gradual decrease and then recovery in copy numbers could be observed for some functional groups and treatments, suggesting that the DNA-based qPCR assays were successful in detecting changes in nitrifier abundances over broader temporal scales (weeks), as already demonstrated in other studies (e.g., Le Roux et al. 2008).

Each of the functional groups studied exhibited distinct responses to a single heat or cold shock. AOB only exhibited responses to heat, consistent with their known sensitivity to heat (Zeng et al. 2014). However, the heat shock in our study reached $\sim 65^{\circ} \mathrm{C}$ and thus is most comparable with the disturbance experienced during strong insolation of topsoil, in addition to conditions in below topsoil exposed to steam disinfestation of soil in the field (Roux-Michollet et al. 2008). It has been shown that AOB follow a similar recovery pattern over time after steam disinfestation as observed in our study (RouxMichollet et al. 2008). Following a heat shock, AOB reached their lowest abundances 18 days after disturbance. This delayed effect may be an indirect result of successional dynamics emerging from the disturbances, which has been shown to last up to 25 days after disturbance in the same experimental system (Jurburg et al. 2017b). In contrast to AOB, AOA were affected by both heat and cold shocks. Previously, AOA have been shown to exhibit higher nitrification potential activities than AOB (Taylor et al. 2017) but a decreased diversity (Daebeler et al. 2012) as temperatures approach $\sim 40{ }^{\circ} \mathrm{C}$. In particular, Daebeler et al. (2012) showed that only a few AOA phylotypes are heat-tolerant. The heat shock used in our study likely fell outside the tolerance range of a portion of the AOA community and therefore resulted in the decreased abundances observed.

Among the AOA, a cold shock resulted in less severe, but still significant reductions in abundance as compared with a heat shock. Soil AOA are more abundant than AOB during freeze-thaw cycles and include cold-adapted archaea (Wang et al. 2012; Alves et al. 2013). For this experiment, however, we used an extreme version of natural freeze-thaw cycles, subjecting the microcosms to extremely cold temperatures $\left(-80^{\circ} \mathrm{C}\right)$ for $6 \mathrm{~h}$. While it was not possible to monitor the soil temperature during this period of cooling down, the 6-h exposure ensured that the microcosms reached below-freezing temperatures. 
We also found that Nitrobacter and Nitrospira were sensitive to both heat and cold shocks. Previously, we found Nitrospira to be highly sensitive to similar heat shocks, as assessed by the sequencing of their 16S rRNA gene transcripts (Nunes et al. 2017), and another study found the temperature sensitivity of NOB to be similar to that of AO (Taylor et al. 2019). In the absence of disturbance, we found a strong relationship between the total number of NOB and the total number of AO in soil, whereas in soils exposed to a heat shock, this relationship was weakened, suggesting that these functional relationships can be altered, leading to decoupling. The decoupling of AO and NOB may lead to the accumulation of nitrite in soil and the release of nitrous oxide, a highly potent greenhouse gas (Graham et al. 2007). Previously, it has been shown that nitrate accumulation occurs in disturbed soils (Calderón et al. 2018). To date, studies of nitrite accumulation in soils (Giguere et al. 2017; Hink et al. 2017; Lu et al. 2018) have focused on the contribution of AOs to nitrite accumulation rather than on the potential of AOs and NOBs to become decoupled. Our findings provide a first glimpse into how disturbance may lead to functional decoupling; however, the complexity of responses shown here warrant further study in a larger-scale experimental setting (i.e., a higher number of replicates and temporal samples).

\section{Effects of compounded disturbances on nitrifier groups}

The type and order of perturbations contribute to the resilience of disturbed soil microbial communities (Jurburg et al. 2017a; Calderón et al. 2018). We hypothesized that the effect of a compounded perturbation (two perturbations in succession) would be more severe if the two disturbances differed, as the diversity of the community's diversity would be progressively eroded, while resilience would be higher in soils which were exposed to the same disturbance twice, as sensitive community members would have already been removed by the first exposure, and the remaining members would be better adapted to a second exposure. For instance, it has been reported that $\mathrm{AOB}$ in gas biofilters exposed to ammonia load shocks of progressively increased intensity become more resistant to extreme ammonia shocks due to a replacement of AOB populations sensitive to high ammonia level by populations resistant to high ammonia (Cabrol et al. 2016). The results obtained for AOA, Nitrobacter, and Nitrospira largely support this view. Indeed, in response to heat shocks, we observed that these three nitrifier groups better withstood a second heat shock when exposed to the same disturbance. The initial heat shock may thus have eliminated the members of each group most susceptible to this perturbation, allowing resistant members within the group to grow and become more dominant during recovery, finally resulting in a more resistant and resilient community in response to the second heat shock.
Similarly, a previous study found that high temperatures can modify both the abundance and composition of the ammoniaoxidizing community (Zeng et al. 2014).

In contrast, $\mathrm{AOB}$ were more sensitive to a heat shock when previously exposed to a first heat shock and even failed to recover 25 days following the second heat shock. This is not consistent with the capacity of AOB to be "trained" by previous disturbances to better resist the same disturbance (e.g., in high ammonia load in nitrifying biofilters; Cabrol et al. 2016). However, in Cabrol et al. (2016), applying ammonia load shocks of progressively increased intensity was needed to allow the AOB community to become more resistant to extreme ammonia shocks. In our study, the heat shock (heating at $65^{\circ} \mathrm{C}$ ) was an extreme ecological challenge for AOB leading to the loss of over $95 \%$ of the community after 18 days. It is possible that this disturbance was too intense given the sensitivity of $\mathrm{AOB}$ to adequately filter only the most sensitive populations.

For all nitrifier groups, the cold shock had less impact on their abundances than the heat shock. When pre-exposed to a heat shock, however, the cold shock disturbance had a stronger effect on the Nitrospira NOB than any other disturbance regime. This was only visible on day 25 , so it is not possible to determine whether this was the beginning of a long-term trend, however. We speculate that the heat and cold disturbances affected different portions of the Nitrospira NOB, resulting in a multiplicative effect of the compounded perturbations, as previously observed for other portions of the soil microbial community (Jurburg et al. 2017a). Curiously, this group was negatively affected by a single heat shock, but was not susceptible upon re-exposure to the same heat disturbance. This was also the case for AOA; we suspect that the more rapid recovery observed for upon re-exposure resulted from the elimination of sensitive group members during the first heat shock.

\section{Links between NEA and abundances of nitrifier groups}

While NEA exhibited a clear response to the disturbance history, no significant correlations were detected between NEA and the abundance of any nitrifier group. Several studies have reported strong links between NEA and AOB or AOA abundance (Hesselsøe et al. 2001; Le Roux et al. 2008; Di et al. 2009), but other studies found no relationship between NEA and the abundance of any nitrifier group (Rudisill et al. 2016; Zhang and Ji 2018; Taylor et al. 2019). This lack of relationship is not unexpected because the nitrification rate per cell can vary depending on nitrifier community composition. Furthermore, NEA is an emergent property from the four nitrifier groups measured, as previously shown for rice paddy soils (Zhang and Ji 2018), which could explain why no relationship was observed between NEA and the abundance of 
single nitrifier group. However, NEA was not better predicted by aggregated variables such as total AO or total NOB abundances, nor abundance ratios. Because NEA measures the quantity of functionally active nitrification in soil (Barnard et al. 2005), it is possible that some disturbances affected the specific activity of nitrifying cells, leading to a large decoupling between NEA and nitrifier abundances. To test this hypothesis, quantifying the amoA gene expression level by RNA-based qPCR would be needed.

\section{Conclusions}

Our study reveals how complex responses to disturbances can emerge from the relatively simple soil nitrification system, mediated by temporal responses and legacy effects, two aspects of the soil microbiome which are seldom considered. Our findings show that functional relationships between ammonia and nitrite oxidizers can be altered and that some soil nitrifier groups may be particularly vulnerable when repeatedly exposed to different disturbances. In order to disentangle how the effects of disturbance propagate through functional interdependencies, future research must acknowledge the emergent complexity of the nitrification system and focus on examining the nitrifying community at a fine temporal resolution with extensive experimental replication.

Acknowledgments We would like to thank M. Wang for the help with the lab work and S. Tem for the valuable discussions.

Code Availability Code is available in https:/github.com/drcarrot/ nitrification-and-disturbance-in-soil.

Authors' contributions SDJ, XLR, JFS, and DvE contributed to the study conception and design. SDJ performed the experiment, SDJ and FLA performed the molecular analyses, SDJ and LB performed statistical analyses, and SDJ and XLR wrote the manuscript.

Funding information Open Access funding provided by Projekt DEAL. This research was supported by the People Programme (Marie Curie Actions) of the European Union's Seventh Framework Programme FP7 2007/2013 under REA Agreement n 289949 (TRAINBIODIVERSE); the German Centre for Integrative Biodiversity Research (iDiv) HalleJena-Leipzig, funded by the German Research Foundation (DFG FZT 118); and INRAe-ECODIV funding. F. Assemien was supported by a $\mathrm{PhD}$ fellowship of the CAMPUS France program (AMRUGE-CI/ SCAC).

Data Availability Data is available in https://github.com/drcarrot/ nitrification-and-disturbance-in-soil.

\section{Compliance with ethical standards}

Conflict of interest The authors declare that they have no conflict of interest.

Ethics approval Not applicable.
Open Access This article is licensed under a Creative Commons Attribution 4.0 International License, which permits use, sharing, adaptation, distribution and reproduction in any medium or format, as long as you give appropriate credit to the original author(s) and the source, provide a link to the Creative Commons licence, and indicate if changes were made. The images or other third party material in this article are included in the article's Creative Commons licence, unless indicated otherwise in a credit line to the material. If material is not included in the article's Creative Commons licence and your intended use is not permitted by statutory regulation or exceeds the permitted use, you will need to obtain permission directly from the copyright holder. To view a copy of this licence, visit http://creativecommons.org/licenses/by/4.0/.

\section{References}

Alves RJE, Wanek W, Zappe A, Richter A, Svenning MM, Schleper C, Urich T (2013) Nitrification rates in Arctic soils are associated with functionally distinct populations of ammonia-oxidizing archaea. ISME J 7:1620-1631

Assémien FL, Pommier T, Gonnety JT, Gervaix J, Le Roux X (2017) Adaptation of soil nitrifiers to very low nitrogen level jeopardizes the efficiency of chemical fertilization in west african moist savannas. Sci Rep 7:1-14. https://doi.org/10.1038/s41598-01710185-5

Attard E, Poly F, Commeaux C, Laurent F, Terada A, Smets BF, Recous S, Le Roux X (2010) Shifts between Nitrospira- and Nitrobacter-like nitrite oxidizers underlie the response of soil potential nitrite oxidation to changes in tillage practices. Environ Microbiol 12:315-326. https://doi.org/10.1111/j.1462-2920.2009.02070.x

Avrahami S, Conrad R (2003) Patterns of community change among ammonia oxidizers in meadow soils upon long-term incubation at different temperatures. Appl Environ Microbiol 69:6152-6164. https://doi.org/10.1128/AEM.69.10.6152-6164.2003

Avrahami S, Liesack W, Conrad R (2003) Effects of temperature and fertilizer on activity and community structure of soil ammonia oxidizers. Environ Microbiol 5:691-705

Bach H, Tomanova J, Schloter M, Munch JC (2002) Enumeration of total bacteria and bacteria with genes for proteolytic activity in pure cultures and in environmental samples by quantitative PCR mediated amplification. J Microbiol Methods 49:235-245

Barnard R, Leadley PW, Hungate BA (2005) Global change, nitrification, and denitrification: a review. Glob Biogeochem Cycles 19:1-13

Cabrol L, Poly F, Malhautier LC, Pommier T, Lerondelle C, Verstraete W, Lepeuple A-S, Fanlo J-L, Le Roux X (2016) Management of microbial communities through transient disturbances enhances the functional resilience of nitrifying gas-biofilters to future disturbances. Environ Sci Technol 50:338-348. https://doi.org/10. 1021/acs.est.5b02740

Calderón K, Philippot L, Bizouard F, Breuil MC, Bru D, Spor A (2018) Compounded disturbance chronology modulates the resilience of soil microbial communities and N-cycle related functions. Front Microbiol 9:1-11. https://doi.org/10.3389/fmicb.2018.02721

Carini P, Marsden PJ, Leff JW, Morgan EE, Strickland MS, Fierer N (2016) Relic DNA is abundant in soil and obscures estimates of soil microbial diversity. Nat Microbiol 2. https://doi.org/10.1038/ nmicrobiol.2016.242

Daebeler A, Abell G, Bodelier P, Bodrossy L, Frampton D, Hefting M, Laanbroek H (2012) Archaeal dominated ammonia-oxidizing communities in Icelandic grassland soils are moderately affected by long-term $\mathrm{N}$ fertilization and geothermal heating. Front Microbiol $3: 352$ 
Daims H, Lebedeva EV, Pjevac P, Han P, Herbold C, Albertsen M, Jehmlich N, Palatinszky M, Vierheilig J, Bulaev A, Kirkegaard $\mathrm{RH}$, von Bergen $\mathrm{M}$, Rattei T, Bendinger B, Nielsen PH, Wagner M (2015) Complete nitrification by Nitrospira bacteria. Nature 528: 504-509. https://doi.org/10.1038/nature16461

Dassonville N, Guillaumaud N, Piola F, Meerts P, Poly F (2011) Niche construction by the invasive Asian knotweeds (species complex Fallopia): impact on activity, abundance and community structure of denitrifiers and nitrifiers. Biol Invasions 13:1115-1133

Di HJ, Cameron KC, Shen JP, Winefield CS, O'Callaghan M, Bowatte S, He JZ (2009) Nitrification driven by bacteria and not archaea in nitrogen-rich grassland soils. Nat Geosci 2:621-624

Dimitri Kits K, Sedlacek CJ, Lebedeva EV, Han P, Bulaev A, Pjevac P, Daebeler A, Romano S, Albertsen M, Stein LY, Daims H, Wagner M (2017) Kinetic analysis of a complete nitrifier reveals an oligotrophic lifestyle. Nature 549:269-272. https://doi.org/10.1038/ nature23679

Gelfand I, Yakir D (2008) Influence of nitrite accumulation in association with seasonal patterns and mineralization of soil nitrogen in a semiarid pine forest. Soil Biol Biochem 40:415-424. https://doi.org/10. 1016/j.soilbio.2007.09.005

Giguere AT, Taylor AE, Suwa Y, Myrold DD, Bottomley PJ (2017) Uncoupling of ammonia oxidation from nitrite oxidation: impact upon nitrous oxide production in non-cropped Oregon soils. Soil Biol Biochem 104:30-38. https://doi.org/10.1016/j.soilbio.2016. 10.011

Graham DW, Knapp CW, Van Vleck ES, Bloor K, Lane TB, Graham CE (2007) Experimental demonstration of chaotic instability in biological nitrification. ISME J 1:385-393. https://doi.org/10.1038/ismej. 2007.45

Hart SC, Stark JM, Davidson EA, Firestone MK (1994) Nitrogen mineralization, immobilization, and nitrification. Methods soil anal part 2-microbiological. In: Biochem prop, pp 985-1018

Hatzenpichler R (2012) Diversity, physiology, and niche differentiation of ammonia-oxidizing archaea. Appl Environ Microbiol 78:75017510. https://doi.org/10.1128/AEM.01960-12

Hesselsøe M, Pedersen A, Bundgaard K, Brandt KK, Sørensen J (2001) Development of nitrification hot-spots around degrading red clover (Trifolium pratense) leaves in soil. Biol Fertil Soils 33:238-245

Hink L, Nicol GW, Prosser JI (2017) Archaea produce lower yields of $\mathrm{N} 2 \mathrm{O}$ than bacteria during aerobic ammonia oxidation in soil. Environ Microbiol 19:4829-4837

Jia Z, Hu X, Xia W, Fornara D, Nannipieri P, Tiedje J (2019) Community shift of microbial ammonia oxidizers in air-dried rice soils after 22 years of nitrogen fertilization. Biol Fertil Soils 55:419-424. https:// doi.org/10.1007/s00374-019-01352-z

Jurburg SD, Nunes I, Brejnrod A, Jacquiod S, Priemé A, Sørensen SJ, Van Elsas JD, Salles JF (2017a) Legacy effects on the recovery of soil bacterial communities from extreme temperature perturbation. Front Microbiol 8:1832

Jurburg SD, Nunes I, Stegen J, Le Roux X, Prieme A, Sørensen S, Salles JF (2017b) Autogenic succession and deterministic recovery following disturbance in soil bacterial communities. Sci Rep 7. https://doi. org $/ 10.1038 /$ srep45691

Kim D-J, Kim S-H (2006) Effect of nitrite concentration on the distribution and competition of nitrite-oxidizing bacteria in nitratation reactor systems and their kinetic characteristics. Water Res 40:887-894

Kitzinger K, Koch H, Lücker S, Sedlacek CJ, Herbold C, Schwarz J, Daebeler A, Mueller AJ, Lukumbuzya M, Romano S, Leisch N, Karst SM, Kirkegaard R, Albertsen M, Nielsen PH, Wagner M, Daims H (2018) Characterization of the first "Candidatus Nitrotoga" isolate reveals metabolic versatility and separate evolution of widespread nitrite-oxidizing bacteria. MBio 9:e01186e01118. https://doi.org/10.1128/mBio.01186-18

Le Roux X, Bouskill NJ, Niboyet A, Barthes L, Dijkstra P, Field CB, Hungate BA, Lerondelle C, Pommier T, Tang J, Terada A, Tourna
M, Poly F (2016) Predicting the responses of soil nitrite-oxidizers to multi-factorial global change: a trait-based approach. Front Microbiol 7:628. https://doi.org/10.3389/fmicb.2016.00628

Le Roux X, Poly F, Currey P, Commeaux C, Hai B, Nicol GW, Prosser JI, Schloter M, Attard E, Klumpp K (2008) Effects of aboveground grazing on coupling among nitrifier activity, abundance and community structure. ISME J 2:221-232. https://doi.org/10.1038/ismej. 2007.109

Leininger S, Urich T, Schloter M, Schwark L, Qi J, Nicol GW, Prosser JI, Schuster SC, Schleper C (2006) Archaea predominate among ammonia-oxidizing prokaryotes in soils. Nature 442:806-809. https://doi.org/10.1038/nature04983

Lenth R, Singmann H, Love J (2018) Emmeans: estimated marginal means, aka least-squares means. $\mathrm{R}$ Packag version 1 :

Lu X, Nicol GW, Neufeld JD (2018) Differential responses of soil ammonia-oxidizing archaea and bacteria to temperature and depth under two different land uses. Soil Biol Biochem 120:272-282. https://doi.org/10.1016/j.soilbio.2018.02.017

Ma W, Jia S, Assemien F, Qin M, Ma B, Xie Z, Liu Y, Feng H, Du G, Ma X, Le Roux X (2016) Response of microbial functional groups involved in soil $\mathrm{N}$ cycle to $\mathrm{N}, \mathrm{P}$ and $\mathrm{NP}$ fertilization in Tibetan alpine meadows. Soil Biol Biochem 101:195-206. https://doi.org/10.1016/ j.soilbio.2016.07.023

Martens-Habbena W, Berube PM, Urakawa H, de la Torre JR, Stahl D a (2009) Ammonia oxidation kinetics determine niche separation of nitrifying Archaea and Bacteria. Nature 461:976-979. https://doi. org/10.1038/nature08465

Nicol GW, Leininger S, Schleper C, Prosser JI (2008) The influence of soil $\mathrm{pH}$ on the diversity, abundance and transcriptional activity of ammonia oxidizing archaea and bacteria. Environ Microbiol 10: 2966-2978

Nowka B, Daims H, Spieck E (2014) Comparison of oxidation kinetics of nitrite-oxidizing bacteria: nitrite availability as a key factor in niche differentiation. Appl Environ Microbiol 81:745-753. https://doi. org/10.1128/AEM.02734-14

Nunes I, Jurburg S, Jacquiod S, Brejnrod A, Salles JF, Priemé A, Sørensen SJ (2017) Soil bacteria show different tolerance ranges to an unprecedented disturbance. Biol Fertil soils 1-14

Ochsenreiter T, Selezi D, Quaiser A, Bonch-Osmolovskaya L, Schleper C (2003) Diversity and abundance of Crenarchaeota in terrestrial habitats studied by $16 \mathrm{~S}$ RNA surveys and real time PCR. Environ Microbiol 5:787-797

Okabe S, Satoh H, Watanabe Y (1999) In situ analysis of nitrifying biofilms as determined by in situ hybridization and the use of microelectrodes. Appl Environ Microbiol 65:3182-3191

Palatinszky M, Herbold C, Jehmlich N, Pogoda M, Han P, von Bergen M, Lagkouvardos I, Karst SM, Galushko A, Koch H, Berry D, Daims H, Wagner M (2015) Cyanate as an energy source for nitrifiers. Nature 524:105-108. https://doi.org/10.1038/nature14856

Pan H, Ying S, Liu H, Zeng L, Zhang Q, Liu Y, Xu J, Li Y, Di H (2018) Microbial pathways for nitrous oxide emissions from sheep urine and dung in a typical steppe grassland. Biol Fertil Soils 54:717-730. https://doi.org/10.1007/s00374-018-1297-2

Pereira e Silva MC, Poly F, Guillaumaud N, van Elsas JD, Salles JF, Silva MC PE (2012) Fluctuations in ammonia oxidizing communities across agricultural soils are driven by soil structure and $\mathrm{pH}$. Front Microbiol 3:77. https://doi.org/10.3389/fmicb.2012.00077

Pester M, Maixner F, Berry D, Rattei T, Koch H, Lücker S, Nowka B, Richter A, Spieck E, Lebedeva E (2014) NxrB encoding the beta subunit of nitrite oxidoreductase as functional and phylogenetic marker for nitrite-oxidizing Nitrospira. Environ Microbiol 16: 3055-3071

Placella SA, Firestone MK (2013) Transcriptional response of nitrifying communities to wetting of dry soil. Appl Environ Microbiol 79: 3294-3302 
Prosser JI, Nicol GW (2012) Archaeal and bacterial ammonia-oxidisers in soil: the quest for niche specialisation and differentiation. Trends Microbiol 20:523-531. https://doi.org/10.1016/j.tim.2012.08.001

Purkhold U, Pommerening-Röser A, Juretschko S, Schmid MC, Koops H-P, Wagner M (2000) Phylogeny of all recognized species of ammonia oxidizers based on comparative $16 \mathrm{~S}$ rRNA and amoA sequence analysis: implications for molecular diversity surveys. Appl Environ Microbiol 66:5368-5382

R Core Team (2014) R: A language and environment for statistical computing

Rotthauwe J-H, Witzel K-P, Liesack W (1997) The ammonia monooxygenase structural gene amoA as a functional marker: molecular fine-scale analysis of natural ammonia-oxidizing populations. Appl Environ Microbiol 63:4704-4712

Roux-Michollet D, Czarnes S, Adam B, Berry D, Commeaux C, Guillaumaud N, Le Roux X, Clays-Josserand a. (2008) Effects of steam disinfestation on community structure, abundance and activity of heterotrophic, denitrifying and nitrifying bacteria in an organic farming soil. Soil Biol Biochem 40:1836-1845. https://doi.org/10. 1016/j.soilbio.2008.03.007

Rudisill MA, Turco RF, Hoagland LA (2016) Fertility practices and rhizosphere effects alter ammonia oxidizer community structure and potential nitrification activity in pepper production soils. Appl Soil Ecol 99:70-77

Schramm A, de Beer D, Wagner M, Amann R (1998) Identification and activities in situ of Nitrosospira and Nitrospira spp. as dominant populations in a nitrifying fluidized bed reactor. Appl Environ Microbiol 64:3480-3485

Simonin M, Le Roux X, Poly F, Lerondelle C, Hungate B, Nunan N, Niboyet A (2015) Coupling between and among ammonia oxidizers and nitrite oxidizers in grassland mesocosms submitted to elevated CO2 and nitrogen supply. Microb Ecol 70:809-818. https://doi.org/ 10.1007/s00248-015-0604-9

Smith P, Cotrufo MF, Rumpel C, Paustian K, Kuikman PJ, Elliott JA, McDowell R, Griffiths RI, Asakawa S, Bustamante M (2015) Biogeochemical cycles and biodiversity as key drivers of ecosystem services provided by soils. Soil Discuss 2:537-586

Stempfhuber B, Richter-Heitmann T, Regan KM, Kölbl A, Wüst PK, Marhan S, Sikorski J, Overmann J, Friedrich MW, Kandeler E (2016) Spatial interaction of archaeal ammonia-oxidizers and nitrite-oxidizing bacteria in an unfertilized grassland soil. Front Microbiol 6:1567

Stephen JR, Chang Y-J, Macnaughton SJ, Kowalchuk GA, Leung KT, Flemming CA, White DC (1999) Effect of toxic metals on indigenous soil $\beta$-subgroup proteobacterium ammonia oxidizer community structure and protection against toxicity by inoculated metalresistant bacteria. Appl Environ Microbiol 65:95-101

Sterngren AE, Hallin S, Bengtson P (2015) Archaeal ammonia oxidizers dominate in numbers, but bacteria drive gross nitrification in $\mathrm{N}$ amended grassland soil. Front Microbiol 6:1350

Taylor AE, Giguere AT, Zoebelein CM, Myrold DD, Bottomley PJ (2017) Modeling of soil nitrification responses to temperature reveals thermodynamic differences between ammonia-oxidizing activity of archaea and bacteria. ISME J 11:896-908
Taylor AE, Myrold DD, Bottomley PJ (2019) Temperature affects the kinetics of nitrite oxidation and nitrification coupling in four agricultural soils. Soil Biol Biochem 136:107523. https://doi.org/10. 1016/j.soilbio.2019.107523

Tourna M, Freitag TE, Nicol GW, Prosser JI (2008) Growth, activity and temperature responses of ammonia-oxidizing archaea and bacteria in soil microcosms. Environ Microbiol 10:1357-1364. https://doi. org/10.1111/j.1462-2920.2007.01563.x

van Kessel MAHJ, Speth DR, Albertsen M, Nielsen PH, Op den Camp HJM, Kartal B, Jetten MSM, Lücker S (2015) Complete nitrification by a single microorganism. Nature 528:555-559. https://doi.org/10. 1038/nature16459

Wang A, Wu F-Z, Yang W-Q, Wu Z-C, Wang X-X, Tan B (2012) Abundance and composition dynamics of soil ammonia-oxidizing archaea in an alpine fir forest on the eastern Tibetan Plateau of China. Can J Microbiol 58:572-580

Wang B, Zhao J, Guo Z, Ma J, Xu H, Jia Z (2015) Differential contributions of ammonia oxidizers and nitrite oxidizers to nitrification in four paddy soils. ISME J 9:1062-1075

Wertz S, Leigh AKK, Grayston SJ (2012) Effects of long-term fertilization of forest soils on potential nitrification and on the abundance and community structure of ammonia oxidizers and nitrite oxidizers. FEMS Microbiol Ecol 79:142-154. https://doi.org/10.1111/j.15746941.2011.01204.x

Wertz S, Poly F, Le Roux X, Degrange V (2008) Development and application of a PCR-denaturing gradient gel electrophoresis tool to study the diversity of Nitrobacter-like nxrA sequences in soil. FEMS Microbiol Ecol 63:261-271. https://doi.org/10.1111/j.15746941.2007.00416.x

Xia F, Wang J-G, Zhu T, Zou B, Rhee S-K, Quan Z-X (2018) Ubiquity and diversity of complete ammonia oxidizers (Comammox). Appl Environ Microbiol 84:e01390-e01318. https://doi.org/10.1128/ AEM.01390-18

Xia W, Zhang C, Zeng X, Feng Y, Weng J, Lin X, Zhu J, Xiong Z, Xu J, Cai Z, Jia Z (2011) Autotrophic growth of nitrifying community in an agricultural soil. ISME J 5:1226-1236. https://doi.org/10.1038/ ismej.2011.5

Xie Z, Le Roux X, Wang C, Gu Z, An M, Nan H, Chen B, Li F, Liu Y, Du $G$ (2014) Identifying response groups of soil nitrifiers and denitrifiers to grazing and associated soil environmental drivers in Tibetan alpine meadows. Soil Biol Biochem 77:89-99. https://doi.org/10. 1016/j.soilbio.2014.06.024

Zeng J, Zhao D, Yu Z, Huang R, Wu QL (2014) Temperature responses of ammonia-oxidizing prokaryotes in freshwater sediment microcosms. PLoS One 9:e100653-e100653. https://doi.org/10.1371/ journal.pone. 0100653

Zhang Y, Ji G (2018) Quantitative responses of potential nitrification and denitrification rates to the size of microbial communities in rice paddy soils. Chemosphere 211:970-977

Publisher's note Springer Nature remains neutral with regard to jurisdictional claims in published maps and institutional affiliations. 